Research Article

\title{
Biological Pretreatment by Solid-State Fermentation of Oat Straw to Enhance Physical Quality of Pellets
}

\author{
Wei Gao, ${ }^{1}$ Zhiqiang Lei, ${ }^{1}$ Lope G Tabil, ${ }^{2}$ and Rongfei Zhao ${ }^{3}{ }^{3}$ \\ ${ }^{1}$ College of Engineering, Shenyang Agricultural University, Shenyang, Liaoning 110866, China \\ ${ }^{2}$ Department of Chemical and Biological Engineering, University of Saskatchewan, Saskatoon, SK, S7N 5A9, Canada \\ ${ }^{3}$ College of Water Conservancy, Shenyang Agricultural University, Shenyang, Liaoning 110866, China
}

Correspondence should be addressed to Rongfei Zhao; rongfeizhao@syau.edu.cn

Received 25 February 2020; Accepted 17 April 2020; Published 25 May 2020

Academic Editor: J. O. Caceres

Copyright (c) 2020 Wei Gao et al. This is an open access article distributed under the Creative Commons Attribution License, which permits unrestricted use, distribution, and reproduction in any medium, provided the original work is properly cited.

\begin{abstract}
Pelleting can increase the efficiency of handling and transportation of biomass. Pretreatment obtains lignin fragments by disrupting the lignocellulosic structure of biomass and ensures the high-quality compressed pellets. In this study, solid-state fermentation (SSF) is used as a biological method to improve the quality of pellets of oat straw. SSF of oat straw using Trametes versicolor 52J (TV52J) and Phanerochaete chrysosporium (PC) was conducted. Response surface methodology (RSM) was employed by using a four-factor, three-level Box-Behnken design with fermentation time (days), moisture content (\%), particle size $(\mathrm{mm})$, and fermentation temperature $\left({ }^{\circ} \mathrm{C}\right)$ as independent parameters. Pellet density, dimensional stability, and tensile strength were the response variables. The optimization options of fermentation time (33.96 and 35 days), moisture content (70\%), particle size $(150$ and $50 \mathrm{~mm})$, and fermentation temperature $\left(22^{\circ} \mathrm{C}\right)$ of oat straw pretreated with these two fungal strains were obtained. The microscopic structural changes of oat straw caused by biological pretreatment were investigated by scanning electron microscopy (SEM). Observation results of SEM showed that the connection between single fibers became relatively loose, and this was beneficial to improve the physical quality of the pellets.
\end{abstract}

\section{Introduction}

With the depletion of fossil fuel resources and the emission of greenhouse gases, it is urgent to find alternative energy sources to ensure the access and safety of energy [1-4]. Lignocellulosic biomass straw has the advantages of rich resources and low cost, which is considered as an important resource of biofuel production. Among all agricultural wastes, cereal straw is the largest biomass raw material, with an annual global output of about $1.5 \mathrm{Gt}[5,6]$.

Due to the irregular shape and low bulk density of dry state of cereal straw, it is difficult to handle, transport, and use as fuel. Bulk density of dry barley straw is approximately $40 \mathrm{~kg} / \mathrm{m}^{3}[7,8]$. This leads to high transportation and storage costs, accounting for more than 35\% of biofuel production expenditures $[9,10]$. In addition, the energy content of biomass in dry state is about half of the coal, which is $16-20 \mathrm{MJ} / \mathrm{kg}$ [7].
Compared with baling, densification can increase the bulk density of the agricultural residue by 7-10 times [11]. Main densification products are cubes, briquettes, and pellets. Pellet provides higher density and unit volume energy for biomass than other two kinds of products [12-14]. Agricultural residues are composed of cellulose, hemicellulose, and lignin, which are arranged into highly recalcitrant structure in the plant cell wall $[15,16]$. Meantime, there are lots of intramolecular and intermolecular hydrogen bonds in straw cellulose, which has a high degree of crystallinity [17]. The lignin structural units are mainly connected by carbon-oxygen bonds, and the carbon-oxygen bonds have high stability to acids, bases, and enzymes [18]. Through chemical, physical, and biological pretreatments, the physical quality of pellets can be improved by changing the structure arrangement of the agricultural residual cellulose-hemicellulose-lignin matrix $[5,19]$. 
Traditional physical and chemical methods are the most commonly used pretreatment technologies, although they need large energy input and will cause pollution. In general, they require expensive corrosion-resistant reactors to deal with a large number of waste streams and treated solids [20]. Pretreatment is a key and expensive step to convert lignocellulosic materials into fuel $[14,21]$. Compared with physical and chemical treatments, microbial treatment of lignocellulosic biomass has the advantages of less investment, simple operation, and no pollution to the environment [22-24]. The hemicellulose and lignin can be destroyed by various microorganisms to make the cellulose crystal structure loose $[17,25]$.

Some microorganisms, for example, white-rot, soft-rot, and brown-rot fungi are used to conduct biological pretreatment to disrupt the fiber structure of biomass [26, 27]. Among them, white-rot fungi are the best in the biological treatment of straw as they can degrade cellulose, hemicellulose, and lignin approximately, effectively, and equally $[14,22]$. White-rot fungi can break down lignin and alter lignocellulose structures as their unique enzymatic machineries, consisting of lignin peroxidase, manganese peroxidase, laccase, and versatile peroxidase [28, 29].

Solid-state fermentation (SSF) and submerged liquid fermentation (SMF) are two kinds of important fungal pretreatments. Compared with SMF, SSF is more suitable for many filamentous fungi to really adapt to the natural environment and has the advantages of low water demand, less energy and capital consumption, and high renewability and productivity [30-33].

Presently, many research studies have been focused on biological pretreatment of lignocellulosic biomass for further enzymatic hydrolysis or saccharification [22, 34]. However, the possibility of densification of biomass after fungal pretreatment is rarely studied. In this study, the feasibility of using SSF as a biological pretreatment method to improve the quality of oat straw particles is investigated. The influence of fungal strain, fermentation time, moisture content, particle size, and fermentation temperature on the density, dimensional stability, and tensile strength of compressed pellets was optimized. Samples of oat straw pellets both untreated and treated corresponding to the optimized SSF conditions were studied to determine the effect of SSF on the biomass particle structure.

\section{Materials and Methods}

2.1. Oat Straw. The testing material was oat straw of variety "Caliber" which was collected shortly after harvest and transferred to the laboratory of University of Saskatchewan from a field in Willner No. 253, Saskatchewan, Canada $\left(51.15^{\circ} \mathrm{N}, 106.36^{\circ} \mathrm{W}\right)$. After one year's storage, the moisture content of oat straw samples was $5.60 \%$ w.b. (wet basis), which was measured by ASAE S358 [35]. The moisture content tests shall be made in triplicate. Oat straw samples were cut into 50,100 , and $150 \mathrm{~mm}$ sections by a crop straw cutting machine (Model CTR, Belfast Mini-Mills Ltd., Belfast, PE, Canada).
2.2. Fungal Strains. Wild types of Trametes versicolor 52J (TV52J) (ATCC 96186) and Phanerochaete chrysosporium (PC) were used in this study [36]. These two kinds of whiterot fungi strains were stored as glycerol stocks at $-80^{\circ} \mathrm{C}$ and grown on Difco Malt Extract Agar (MEA) (Benton Dickenson, Sparks, MD).

2.3. Solid-State Fermentation. 10 agar plugs (diameter $0.5 \mathrm{~cm}$ ) were removed from the edge of the colony growing on the malt extract agar plate with the wide edge of the pasteurized straw and then added to the malt extract broth (MEB) to prepare the fungal liquid preculture. The mixture was mixed in an Eberbach mixing cup at full speed ( 3 pulses per 10 seconds) on the base of a warm water mixer and then stirred $(150 \mathrm{rpm})$ at room temperature $\left(20-22^{\circ} \mathrm{C}\right)$ for 2 days. The preculture was mixed with $\operatorname{MEB}(1: 5$ dilution) to prepare the SSF culture agent.

In order to avoid the growth of endogenous microorganisms, the substrate (chopped straw) was sterilized at $121^{\circ} \mathrm{C}$ for 10 minutes [35]. Then, $20 \mathrm{~g}$ of sterilized biomass was placed in the plastic ventilation bag, which was designed with small holes around so that gas exchange could be carried out at the same time of keeping sterile and humid environment. A uniform liquid fungal culture $(10 \mathrm{ml})$ was inoculated on the substrate and evenly distributed with a pipette. The moisture content of the culture was adjusted to $60 \%$ w.b., $65 \%$ w.b., and $70 \%$ w.b. with distilled water. The manual bag sealer was used to close the bags, and they were incubated at 22,28 , and $34^{\circ} \mathrm{C}$ for 21,28 , and 35 days. The effects of these two fungi on oat straw were tested (shown in Figure 1(a)). After incubation, the corresponding bags were opened, the chopped oat straw was dried at room temperature for 1-2 days, and then were grinded for densification using a grinder (SM1, Retsch Technology GmbH, Haan, Germany) with 1.6 and $1.0 \mathrm{~mm}$ sieves (shown in Figure 1(b)).

2.4. Design of the Experiment. In this study, the coded factor levels and actual values of independent variables are shown in Table 1. The analysis of variance (ANOVA) and the response surface method (RSM) were used to determine the regression equations expressing the influence of fermentation time, moisture content, particle size, and fermentation temperature on density 0 (pellet density immediately after pelleting), density 1 (pellet density 14 days after pelleting), dimensional stability, and tensile strength of oat straw samples [37, 38]. The independent variables (influencing factors) were fermentation time, moisture content, particle size, and fermentation temperature. Box-Behnken experimental design was used to design and analyze the experiments by software DesignExpert. Every independent variable has three selected levels. After tests, the response variables such as density 0 , density 1, dimensional stability, and tensile strength affected by independent variables could be calculated and defined as follows: 


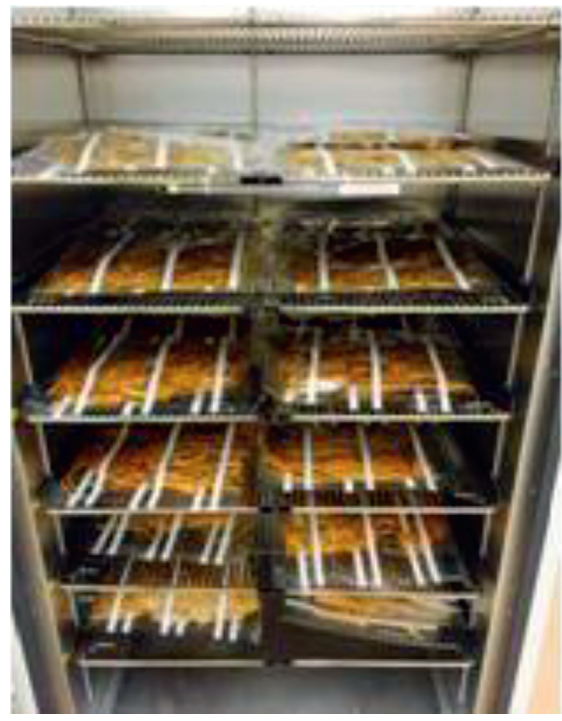

(a)

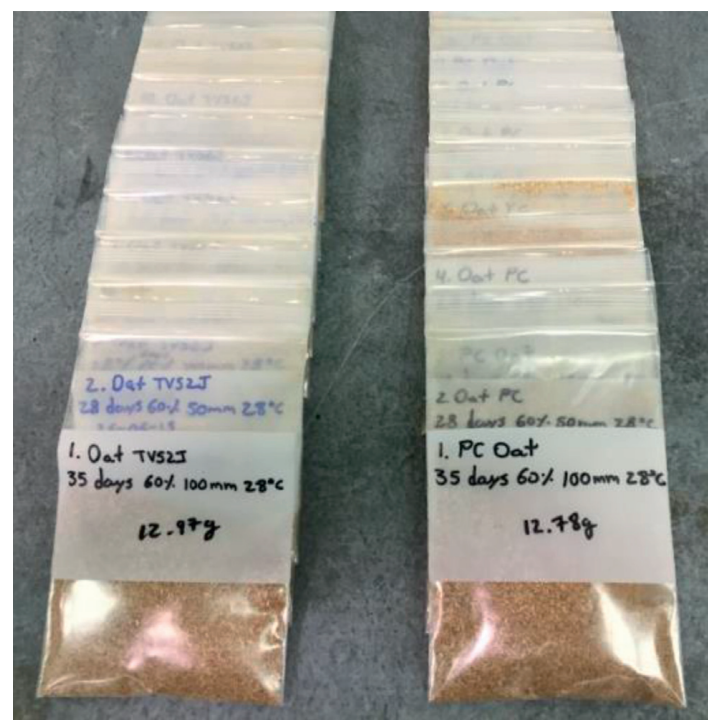

(b)

FIgURE 1: Solid-state fermentation process of oat straw samples. (a) Pretreatment of samples. (b) Pretreated samples.

$$
y_{n}=\beta_{0}+\sum_{i=1}^{4} \beta_{i} x_{i}+\sum_{i=1}^{4} \beta_{i i} x_{i}^{2}+\sum_{i=1}^{3} \sum_{j=i+1}^{4} \beta_{i j} x_{i} x_{j} \quad(n=1,2,3,4),
$$

where $y_{1}$ is density $0, \mathrm{~kg} / \mathrm{m}^{3} ; y_{2}$ is density $1, \mathrm{~kg} / \mathrm{m}^{3} ; y_{3}$ is the dimensional stability, $\% ; y_{4}$ is the tensile strength, $\mathrm{MPa} ; x_{1}$ is the fermentation time, days; $x_{2}$ is the moisture content, \% w.b.; $x_{3}$ is the particle size, $\mathrm{mm} ; x_{4}$ is the fermentation temperature, ${ }^{\circ} \mathrm{C}$; and $\beta_{0}, \beta_{i}, \beta_{i i}$, and $\beta_{i j}$ are the regression coefficients of intercept terms, linear terms, quadratic terms, and interaction terms in the equation, respectively.

2.5. Densification of Oat Straw. A single pelleting unit (SPU) was installed on an Instron tester (Model No. 3366, Instron Corp., Norwood, MA) which was used to densify the biological pretreated oat straw [6]. There were a fixed steel cylindrical die and a moving plunger connected with the upper crosshead which supported $4 \mathrm{kN}$ load to compress the oat straw at a speed of $50 \mathrm{~mm} / \mathrm{min}$. A heating element was entwined out of the die to provide required heat $\left(95 \pm 0.3^{\circ} \mathrm{C}\right)$ [2]. About $0.50 \mathrm{~g}$ of pretreated crushed oat straw was put into the die before pelleting. Five pellets were compressed for each kind of treated straw and were stored at room temperature.

2.6. Density and Dimensional Stability of the Pellet. The density of the oat straw pellet was the quotient of mass and volume which could be obtained by measuring the values of mass, length, and diameter of pellets by a JJ-200Y highprecision electronic balance (measurement accuracy is $0.01 \mathrm{~g}$ ) and a 125MEA-6/150 Vernier caliper. After 14 days of pelleting, the dimensional stability of the pellets could be used to evaluate the volume change. The calculation formula of dimensional stability of pellets is shown as follows:
TABle 1: Coded levels for influencing factors used in the experiment.

\begin{tabular}{lcccc}
\hline Code & \multicolumn{4}{c}{ Factor } \\
$z_{j}$ & $x_{1}(\mathrm{~d})$ & $x_{2}(\%)$ & $x_{3}(\mathrm{~mm})$ & $x_{4}\left({ }^{\circ} \mathrm{C}\right)$ \\
\hline 1 & 35 & 70 & 150 & 34 \\
0 & 28 & 65 & 100 & 28 \\
-1 & 21 & 60 & 50 & 22 \\
$\Delta j$ & 7 & 5 & 50 & 6 \\
\hline
\end{tabular}

$z_{j}$ is the level of each influencing factor.

$$
\text { Dimensional stability }=\left[\frac{\mathrm{Vol}_{14}-\mathrm{Vol}_{0}}{\mathrm{Vol}_{0}}\right] \times 100 \%,
$$

where $\mathrm{Vol}_{0}$ is the volume of pellets right after pelleting, $\mathrm{mm}^{3}$ and $\mathrm{Vol}_{14}$ is the volume of pellets 14 days after pelleting, $\mathrm{mm}^{3}$.

2.7. Tensile Strength of the Pellet. According to the diametral compression experiment carried out with the Instron tester, tensile strength of the pellet was measured [6]. Before the experiment, the pellets were cut into $2.5 \mathrm{~mm}$ thick specimens with a scalpel along the diameter. Each sample was laid on its edge and compressed with $1 \mathrm{kN}$ load force by an upper plunger at $1 \mathrm{~mm} / \mathrm{min}$ until failure occurred. The forces which divided the specimens into halves along the loading axis were adopted. Each sample carried out 5 repeated experiments. The calculation formula of tensile strength of pellets is shown as follows:

$$
\delta_{x}=\frac{2 F}{\pi d l}
$$

where $\delta_{x}$ is the tensile (horizontal) stress, MPa; $F$ is the load at fracture, $\mathrm{N} ; d$ is the specimen diameter, $\mathrm{mm}$; and $l$ is the specimen length, $\mathrm{mm}$. 
2.8. Scanning Electron Microscopy (SEM) of Oat Straw Samples Produced the Pellets with the Highest Tensile Strength. SEM (G2 Pure, Manufacturer: Phenom-World, Eindhoven, Netherlands) was used to observe the changes of the surface structure and cross section of pretreated and untreated oat straw $[39,40]$. Before SEM observation, the oat straw samples were coated with gold for $120 \mathrm{~s}$ with a gold sputtering coater (Edwards S150B, North Walsham, $\mathrm{UK})$.

\section{Results and Discussion}

The experimental results are shown in Table 2. The average tensile strength of pellets made from oat straw pretreated with TV52J and PC varied from 0.169 to $0.362 \mathrm{MPa}$ and 0.147 to $0.279 \mathrm{MPa}$, respectively. Meanwhile, the dimensional stability of pellets ranged between $0.88 \%$ and $4.26 \%$ and $0.58 \%$ and $4.68 \%$; pellet density 1 ranged between 986 and $1063 \mathrm{~kg} / \mathrm{m}^{3}$ and 960 and $1057 \mathrm{~kg} / \mathrm{m}^{3}$; and pellet density 0 ranged between 1,002 and $1,076 \mathrm{~kg} / \mathrm{m}^{3}$ and 984 and $1,075 \mathrm{~kg} / \mathrm{m}^{3}$, respectively.

3.1. Analysis of Variance. After stepwise regression, the analysis of variance (ANOVA) of density 0 , density 1, dimensional stability, and tensile strength influenced by fermentation time, moisture content, particle size, and fermentation temperature is summarized in Tables 3 and 4. $P$ values of all response variables' models were no more than 0.05 which meant that all models were significant. Meantime, $P$ values of all response variables' lack of fits were more than 0.05 which meant that all models fitted the data well.

The fermentation time had extremely significant influences on density 0 of pellets produced with TV52J and PC pretreated oat straw and density 1 and tensile strength of pellets produced with PC pretreated oat straw and significant influences on dimensional stability of pellets produced with TV52J and PC pretreated oat straw and tensile strength of pellets produced with TV52J pretreated oat straw. The moisture content had extremely significant influences on density 0 and tensile strength of pellets produced with PC pretreated oat straw and significant influences on dimensional stability of pellets produced with TV52J pretreated oat straw. The particle size had significant influences on dimensional stability of pellets produced with TV52J pretreated oat straw. The fermentation temperature had extremely significant influences on all responses except the dimensional stability of pellets produced with PC pretreated oat straw.

3.2. Effect of Independent Variables on All Responses for Two Kinds of Fungal Strains. The results in Tables 3 and 4 show that the models could enough describe the response surface of pellet's density 0 , density 1 , dimensional stability, and tensile strength. The response surface models of optimization and prediction were considered feasible. The final regression models of the response variables and the corresponding multiple determination coefficients $\left(R^{2}\right)$ are shown in Table 5.
According to the results of Tables 3-5, the interaction effects of independent variables on all responses of pellets produced with the oat straw pretreated by TV52J and PC generated by Design-Expert software are shown in Figures 2 and 3.

According to Figure 2, for the pellets produced by the oat straw pretreated with TV52J, density 0 increased with increasing of particle size under conditions of long fermentation time, high moisture content, and low fermentation temperature, and it decreased with increasing of particle size under conditions of short fermentation time, low moisture content, and high fermentation temperature; the tensile strength increased at high moisture content and decreased at low moisture content with increasing of particle size, and it increased at big particle size and decreased at small particle size with increasing of moisture content.

According to Figure 3, for the pellets produced by the oat straw pretreated with PC, density 0 generally increased at high moisture content and decreased at low moisture content with increasing of fermentation time, and it increased at long fermentation time and decreased at short fermentation time with increasing of moisture content; density 0 increased at any particle size with decreasing of fermentation temperature, and it increased at high fermentation temperature and decreased at low fermentation temperature with increasing of particle size; and the dimensional stability increased at high fermentation temperature and decreased at low fermentation temperature generally with increasing of fermentation time, and it increased at long fermentation time and decreased at short fermentation time with increasing of fermentation temperature.

3.3. Optimal Combination Solution. The optimal goals are obtaining maximized density 0 , density 1 , tensile strength, and minimized dimensional stability which are shown in Table 6. Tensile strength of the pellet was a good indicator of the physical resistance of pellets to the forces during handling and transportation, and this property was the most important response variable. Low value of dimensional stability of the pellet meant good handling and less dust generation [6], and it was the second most important response variable. High values of density 1 and density 0 were also desirable properties for pellet treatment. For the goals related to the response variables, the independent variables, such as fermentation time, moisture content, particle size, and fermentation temperature were placed "in range."

The top two optimization results of responses of pellets produced by the oat straw pretreated with two kinds of fungal strains are presented in Table 7. For the pellets produced by the oat straw pretreated with TV52J, 33.96 days fermentation time, $70 \%$ moisture content, $150 \mathrm{~mm}$ particle size, and $22^{\circ} \mathrm{C}$ fermentation temperature were chosen to be the best fermentation conditions due to the high tensile strength of $0.395 \mathrm{MPa}$, low dimensional stability of $1.071 \%$, high density 1 of $1,070 \mathrm{~kg} / \mathrm{m}^{3}$, and density 0 of $1,104 \mathrm{~kg} / \mathrm{m}^{3}$. For the pellets produced by the oat straw pretreated with PC, high tensile strength of $0.294 \mathrm{MPa}$, low dimensional stability 
TABLe 2: Physical properties of oat straw pellets based on the Box-Behnken experimental design.

\begin{tabular}{|c|c|c|c|c|c|c|c|c|c|c|c|c|}
\hline \multirow{3}{*}{ Runs } & \multirow{2}{*}{\multicolumn{4}{|c|}{ Variables }} & \multicolumn{8}{|c|}{ Responses } \\
\hline & & & & & \multicolumn{4}{|c|}{ Fungi: TV52J } & \multicolumn{4}{|c|}{ Fungi: PC } \\
\hline & $x_{1}(\mathrm{~d})$ & $x_{2}(\%)$ & $x_{3}(\mathrm{~mm})$ & $x_{4}\left({ }^{\circ} \mathrm{C}\right)$ & $\begin{array}{c}y_{1} \\
\left(\mathrm{~kg} / \mathrm{m}^{3}\right)\end{array}$ & $\begin{array}{c}y_{2} \\
\left(\mathrm{~kg} / \mathrm{m}^{3}\right)\end{array}$ & $y_{3}(\%)$ & $y_{4}(\mathrm{MPa})$ & $\begin{array}{c}y_{1} \\
\left(\mathrm{~kg} / \mathrm{m}^{3}\right)\end{array}$ & $\begin{array}{c}y_{2} \\
\left(\mathrm{~kg} / \mathrm{m}^{3}\right)\end{array}$ & $y_{3}(\%)$ & $y_{4}(\mathrm{MPa})$ \\
\hline 1 & 1 & 0 & -1 & 0 & 1,044 & 1,009 & 1.68 & 0.265 & 1,041 & 1,016 & 1.32 & 0.229 \\
\hline 2 & 0 & 1 & 1 & 0 & 1,051 & 1,026 & 1.70 & 0.275 & 1,052 & 1,010 & 2.08 & 0.238 \\
\hline 3 & -1 & 1 & 0 & 0 & 1,009 & 991 & 1.83 & 0.248 & 984 & 975 & 1.33 & 0.179 \\
\hline 4 & 0 & -1 & -1 & 0 & 1,047 & 1,022 & 2.06 & 0.256 & 1,025 & 999 & 0.89 & 0.214 \\
\hline 5 & 1 & 0 & 0 & -1 & 1,063 & 1,029 & 1.17 & 0.295 & 1,075 & 1,057 & 0.58 & 0.271 \\
\hline 6 & 0 & 0 & 0 & 0 & 1,029 & 991 & 2.80 & 0.239 & 1,045 & 1,036 & 1.58 & 0.260 \\
\hline 7 & 0 & 0 & 0 & 0 & 1,039 & 1,032 & 2.69 & 0.210 & 1,037 & 1,022 & 4.63 & 0.233 \\
\hline 8 & -1 & 0 & 1 & 0 & 1,002 & 986 & 2.96 & 0.185 & 1,005 & 985 & 0.87 & 0.190 \\
\hline 9 & 0 & 1 & 0 & -1 & 1,071 & 1,045 & 1.29 & 0.325 & 1,060 & 1,025 & 3.02 & 0.245 \\
\hline 10 & 1 & 0 & 0 & 1 & 1,040 & 1,008 & 1.52 & 0.244 & 1,031 & 1,019 & 3.67 & 0.232 \\
\hline 11 & -1 & 0 & 0 & -1 & 1,052 & 1,030 & 2.05 & 0.259 & 1,020 & 1,001 & 1.72 & 0.198 \\
\hline 12 & 0 & -1 & 1 & 0 & 1,032 & 1,030 & 1.58 & 0.184 & 1,044 & 1,021 & 3.37 & 0.237 \\
\hline 13 & 0 & 0 & 1 & -1 & 1,076 & 1,063 & 1.44 & 0.362 & 1,053 & 1,022 & 2.66 & 0.268 \\
\hline 14 & -1 & 0 & 0 & 1 & 1,028 & 1,005 & 4.26 & 0.198 & 996 & 962 & 0.92 & 0.192 \\
\hline 15 & 0 & 0 & -1 & -1 & 1,049 & 1,023 & 0.88 & 0.262 & 1,071 & 1,034 & 2.40 & 0.279 \\
\hline 16 & 0 & -1 & 0 & 1 & 1,025 & 997 & 2.77 & 0.217 & 1,033 & 993 & 4.12 & 0.186 \\
\hline 17 & -1 & -1 & 0 & 0 & 1,012 & 991 & 3.58 & 0.221 & 991 & 960 & 1.15 & 0.147 \\
\hline 18 & 0 & 0 & 1 & 1 & 1,011 & 1,000 & 3.97 & 0.197 & 1,047 & 1,007 & 4.68 & 0.217 \\
\hline 19 & 0 & -1 & 0 & -1 & 1,066 & 1,041 & 2.43 & 0.277 & 1,046 & 1,016 & 3.19 & 0.240 \\
\hline 20 & -1 & 0 & -1 & 0 & 1,031 & 999 & 1.47 & 0.229 & 989 & 972 & 1.83 & 0.187 \\
\hline 21 & 0 & 0 & -1 & 1 & 1,035 & 1,000 & 1.61 & 0.169 & 1,029 & 985 & 2.51 & 0.215 \\
\hline 22 & 0 & 1 & 0 & 1 & 1,036 & 993 & 1.97 & 0.182 & 1,047 & 998 & 2.98 & 0.235 \\
\hline 23 & 1 & 0 & 1 & 0 & 1,054 & 1,016 & 3.06 & 0.284 & 1,040 & 1,019 & 3.03 & 0.237 \\
\hline 24 & 1 & -1 & 0 & 0 & 1,037 & 995 & 1.63 & 0.243 & 1,022 & 1,007 & 2.06 & 0.183 \\
\hline 25 & 0 & 1 & -1 & 0 & 1,024 & 1,016 & 0.92 & 0.214 & 1,051 & 1,034 & 2.28 & 0.245 \\
\hline 26 & 1 & 1 & 0 & 0 & 1,036 & 1,003 & 1.18 & 0.228 & 1,065 & 1,034 & 1.80 & 0.257 \\
\hline 27 & 0 & 0 & 0 & 0 & 1,027 & 995 & 3.22 & 0.227 & 1,031 & 1,002 & 2.62 & 0.207 \\
\hline 28 & 0 & 0 & 0 & 0 & 1,034 & 991 & 1.56 & 0.252 & 1,040 & 1,020 & 1.85 & 0.226 \\
\hline 29 & 0 & 0 & 0 & 0 & 1,035 & 1,010 & 2.40 & 0.280 & 1,032 & 1,004 & 1.43 & 0.206 \\
\hline
\end{tabular}

TABLE 3: Coefficient values of the fitting model for different responses of oat straw pellets pretreated with TV52J.

\begin{tabular}{|c|c|c|c|c|c|c|}
\hline Response variable & Source & $\mathrm{df}$ & Sum of squares & Mean squares & $F$ value & $P$ value \\
\hline \multirow{9}{*}{ Density 0} & Model & 14 & 8079.23 & 577.09 & 7.56 & 0.0003 \\
\hline & $x_{1}$ & 1 & 1664.51 & 1664.51 & 21.81 & 0.0004 \\
\hline & $x_{4}$ & 1 & 3352.36 & 3352.36 & 43.93 & $<0.0001$ \\
\hline & $x_{1} x_{3}$ & 1 & 365.19 & 365.19 & 4.79 & 0.0462 \\
\hline & $x_{2} x_{3}$ & 1 & 462.25 & 462.25 & 6.06 & 0.0275 \\
\hline & $x_{3} x_{4}$ & 1 & 639.33 & 639.33 & 8.38 & 0.0118 \\
\hline & $x_{4}^{2}$ & 1 & 1266.17 & 1266.17 & 16.59 & 0.0011 \\
\hline & Lack of fit & 10 & 975.30 & 97.53 & 4.19 & 0.0900 \\
\hline & Model & 14 & 7815.07 & 558.22 & 2.84 & 0.0304 \\
\hline \multirow{3}{*}{ Density 1} & $x_{4}$ & 1 & 4384.98 & 4384.98 & 22.28 & 0.0003 \\
\hline & $x_{4}^{2}$ & 1 & 1294.49 & 1294.49 & 6.58 & 0.0225 \\
\hline & Lack of fit & 10 & 923.37 & 92.34 & 0.50 & 0.8297 \\
\hline \multirow{6}{*}{ Dimensional stability } & Model & 14 & 16.66 & 1.19 & 2.80 & 0.0318 \\
\hline & $x_{1}$ & 1 & 2.91 & 2.91 & 6.86 & 0.0202 \\
\hline & $x_{2}$ & 1 & 2.22 & 2.22 & 5.23 & 0.0383 \\
\hline & $x_{3}$ & 1 & 3.09 & 3.09 & 7.28 & 0.0173 \\
\hline & $x_{4}$ & 1 & 3.90 & 3.90 & 9.18 & 0.0090 \\
\hline & Lack of fit & 10 & 4.41 & 0.44 & 1.15 & 0.4846 \\
\hline \multirow{5}{*}{ Tensile strength } & Model & 14 & 0.042 & 0.003 & 3.64 & 0.0107 \\
\hline & $x_{1}$ & 1 & 0.004 & 0.004 & 4.79 & 0.0460 \\
\hline & $x_{4}$ & 1 & 0.027 & 0.027 & 32.81 & $<0.0001$ \\
\hline & $x_{2} x_{3}$ & 1 & 0.004 & 0.004 & 5.30 & 0.0371 \\
\hline & Lack of fit & 10 & 0.009 & 0.0009 & 1.27 & 0.4421 \\
\hline
\end{tabular}


TABLe 4: Coefficient values of the fitting model for different responses of oat straw pellets pretreated with PC.

\begin{tabular}{|c|c|c|c|c|c|c|}
\hline Response variable & Source & $\mathrm{df}$ & Sum of squares & Mean squares & $F$ value & $P$ value \\
\hline \multirow{9}{*}{ Density 0} & Model & 14 & 14983.37 & 1070.24 & 26.34 & $<0.0001$ \\
\hline & $x_{1}$ & 1 & 6960.08 & 6960.08 & 171.31 & $<0.0001$ \\
\hline & $x_{2}$ & 1 & 805.24 & 805.24 & 19.82 & 0.0005 \\
\hline & $x_{4}$ & 1 & 1673.24 & 1673.24 & 41.18 & $<0.0001$ \\
\hline & $x_{1} x_{2}$ & 1 & 643.89 & 643.89 & 15.85 & 0.0014 \\
\hline & $x_{3} x_{4}$ & 1 & 327.43 & 327.43 & 8.06 & 0.0131 \\
\hline & $x_{1}^{2}$ & 1 & 2616.91 & 2616.91 & 64.41 & $<0.0001$ \\
\hline & $x_{4}^{\frac{1}{2}}$ & 1 & 764.54 & 764.54 & 18.82 & 0.0007 \\
\hline & Lack of fit & 10 & 435.63 & 43.56 & 1.31 & 0.4280 \\
\hline \multirow{5}{*}{ Density 1} & Model & 14 & 13279.73 & 948.55 & 8.15 & 0.0002 \\
\hline & $x_{1}$ & 1 & 7333.44 & 7333.44 & 63.02 & $<0.0001$ \\
\hline & $x_{4}$ & 1 & 3107.30 & 3107.30 & 26.70 & 0.0001 \\
\hline & $x_{1}^{2}$ & 1 & 1219.17 & 1219.17 & 10.48 & 0.0060 \\
\hline & Lack of fit & 10 & 923.37 & 92.34 & 0.52 & 0.8148 \\
\hline \multirow{4}{*}{ Dimensional stability } & Model & 14 & 25.06 & 1.79 & 2.65 & 0.0396 \\
\hline & $x_{1} x_{4}$ & 1 & 3.78 & 3.78 & 5.59 & 0.0330 \\
\hline & $x_{1}^{2}$ & 1 & 5.79 & 5.79 & 8.57 & 0.0110 \\
\hline & Lack of fit & 10 & 2.54 & 0.25 & 0.15 & 0.9936 \\
\hline \multirow{6}{*}{ Tensile strength } & Model & 14 & 0.024 & 0.002 & 5.79 & 0.0011 \\
\hline & $x_{1}$ & 1 & 0.008 & 0.008 & 28.66 & 0.0001 \\
\hline & $x_{2}$ & 1 & 0.003 & 0.003 & 10.58 & 0.0058 \\
\hline & $x_{4}$ & 1 & 0.004 & 0.004 & 14.40 & 0.0020 \\
\hline & $x_{1}^{2}$ & 1 & 0.003 & 0.003 & 10.97 & 0.0051 \\
\hline & Lack of fit & 10 & 0.002 & 0.0002 & 0.43 & 0.8744 \\
\hline
\end{tabular}

of $1.14 \%$, high density 1 of $1,068 \mathrm{~kg} / \mathrm{m}^{3}$, and density 0 of $1,108 \mathrm{~kg} / \mathrm{m}^{3}$ could be achieved with fermentation conditions of 35 days fermentation time, $70 \%$ moisture content, $50 \mathrm{~mm}$ particle size, and $22^{\circ} \mathrm{C}$ fermentation temperature.

The optimal values of moisture content and fermentation temperature of oat straw pretreated with TV52J and PC were very similar. Asgher et al. [41] carried out the solidstate cultivation on corn cobs with PC in moisture content ranging between $40 \%$ and $90 \%$ and found that strongest ligninase activity occurred at $70 \%$ moisture content condition. Shi et al. [42] conducted cultivation on cotton stalks by PC; $27.6 \%$ lignin degradation was obtained at $75 \%$ moisture content in the substrate, which was about $7 \%$ higher than that at $65 \%$ moisture content. Generally, high moisture content was beneficial to the formation of fungal mycelium but not necessarily to the increase of delignification [43]. Temperature ranging from 25 to $30^{\circ} \mathrm{C}$ was optimal for high delignification rate of white-rot Basidiomycetes $[44,45]$. Wan and $\mathrm{Li}[46]$ investigated the influence of temperature on pretreatment of corn stover by C. subvermispora within a temperature ranging between 4 and $37^{\circ} \mathrm{C}$ and found $28^{\circ} \mathrm{C}$ was the optimal temperature for boosting enzymatic digestibility to corn stover.

There were some differences about optimized fermentation time of oat straw pretreated with TV52J and PC, and the time was 33.96 and 35 days, respectively. Rudakiya and Gupte [47] pretreated two Indian hardwoods by Pseudolagarobasidium acaciicola AGST3 and Tricholoma giganteum AGDR1 and reported that lignocellulosic decomposition activity of two kinds of fungi would decrease after 30 days. Generally, the high degree of lignin degradation could be obtained after several weeks to months. Research studies indicated that a few days to weeks were enough for PC to realize vigorous degradation without distinction of lignin and holocellulose, which was not beneficial for biofuel production $[48,49,50]$. There existed significant differences in optimal values of particle size for two kinds of pretreated fungal strains. Wan and Li [46] carried out the pretreated corn stover with Ceriporiopsis subvermispora and showed that the microbial delignification of the corn stover was $12.83-24.90 \%$ and $19.48-31.59 \%$ when the particle sizes were $15 \mathrm{~mm}$ and $5 \mathrm{~mm}$, respectively. Gao et al. [51] carried out the granulation test of corn straw. The results showed that the highest compressive strength of pellets produced with straw treated by PC was $0.261 \mathrm{MPa}$, which was 1.72 times of the pellets without pretreatment, and the corresponding pretreatment conditions was 30 days fermentation time and $50 \mathrm{~mm}$ particle size. Generally, before densification, in order to obtain better pretreatment effect, reduction in the particle size was crucial for increasing the surface area of lignocellulosic biomass $[52,53]$.

3.4. SEM of Untreated and Treated Oat Straw. Tensile strength was the most important physical property for pellets. SEM images of untreated and treated oat straw were used to test the influence of biological pretreatment on the tensile strength of pellets. The oat straw materials used for SEM were taken from runs 13 and 15 (in Table 2) that were pretreated with TV52J and PC, respectively. Figures 4(a)4(c) and 5(a)-5(c) showed the longitudinal sections of oat straw samples before and after pretreatment. As shown in Figures 4(a) and 5(a), the outer and the inner surface structure of untreated oat straw were all smooth, but the 


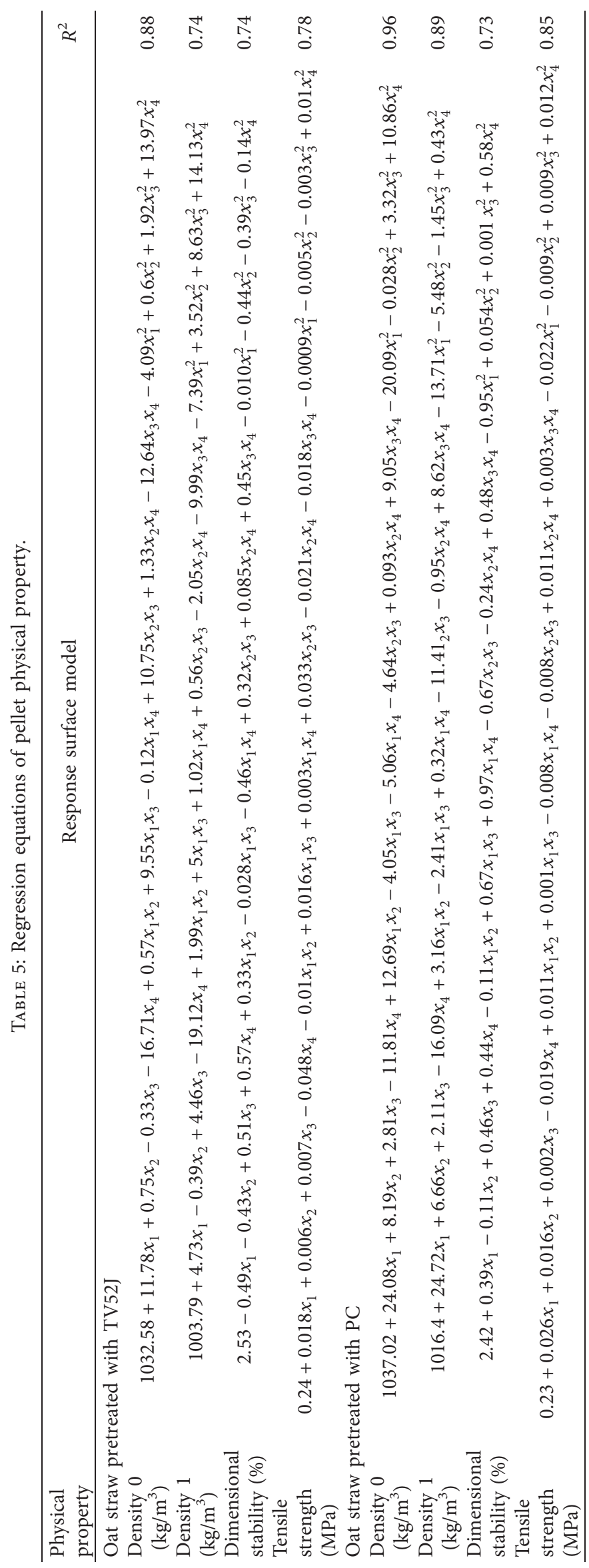




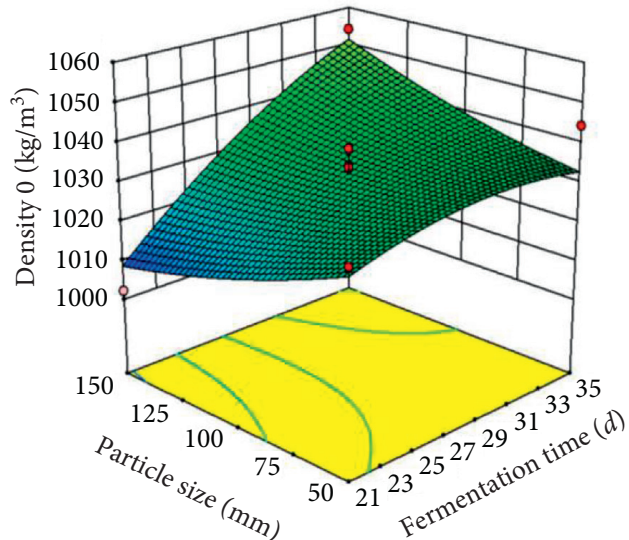

(a)

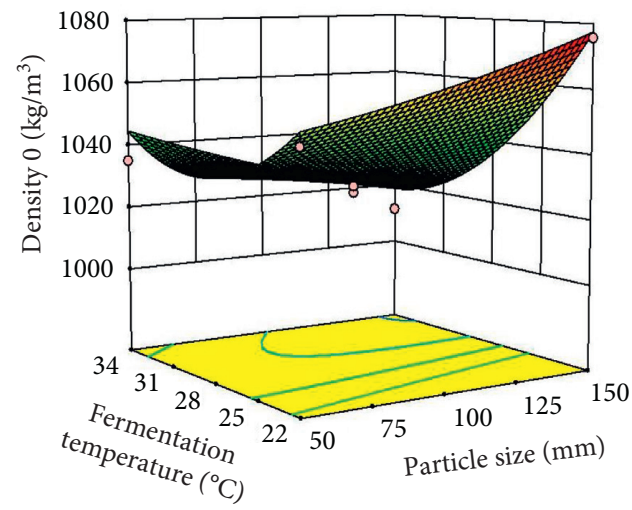

(c)

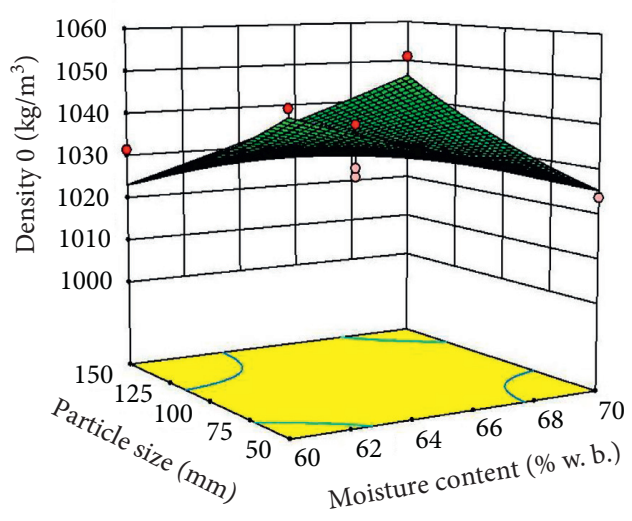

(b)

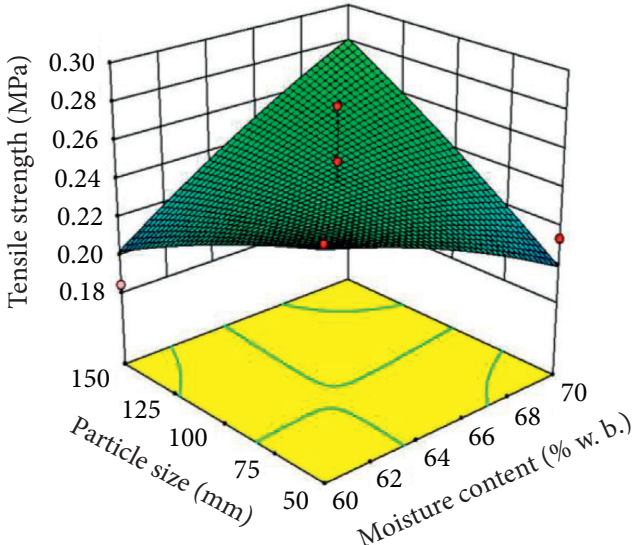

(d)

FIGURE 2: Interaction effects of independent variables on the responses of pellets produced by the oat straw pretreated with TV52. (a) Interaction between particle size and fermentation time on density 0 . (b) Interaction between particle size and moisture content on density 0 . (c) Interaction between fermentation temperature and particle size on density 0 . (d) Interaction between particle size and moisture content on the tensile strength.

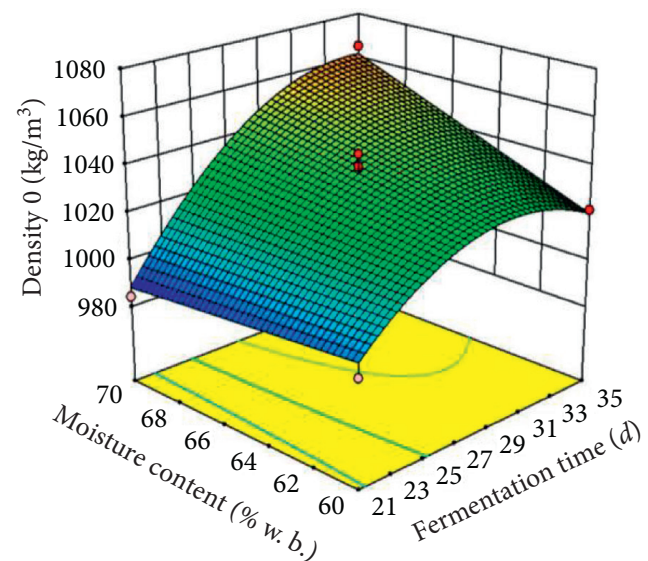

(a)

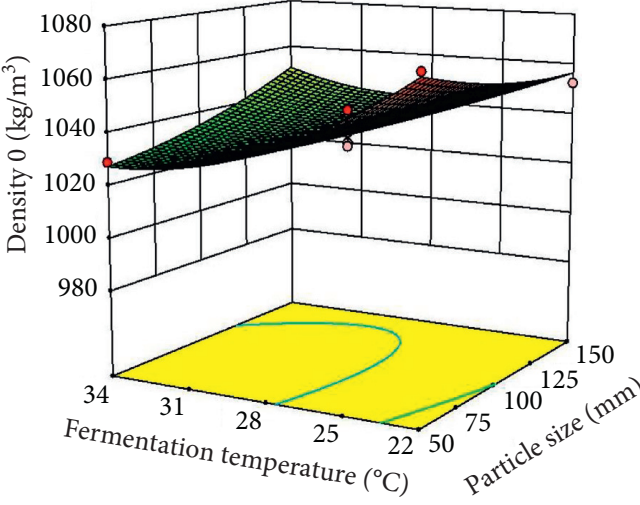

(b)

Figure 3: Continued. 


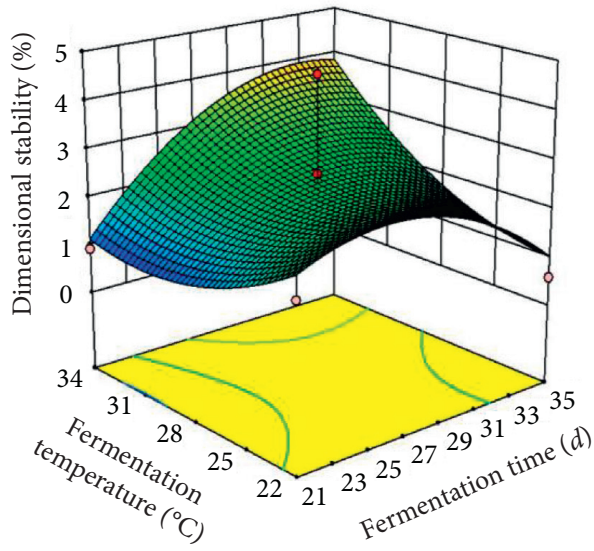

(c)

FIGURE 3: Interaction effects of independent variables on the responses of pellets produced by the oat straw pretreated with PC. (a) Interaction between moisture content and fermentation time on density 0 . (b) Interaction between fermentation temperature and particle size on density 0 . (c) Interaction between fermentation temperature and fermentation time on the dimensional stability.

TABLE 6: Optimization objectives of variables in the experimental pelleting of pretreated oat straw.

\begin{tabular}{lcc}
\hline Variable & Goal & Level of importance \\
\hline Independent & & \\
Fermentation time $(d)$ & In range $(21$ to 35$)$ \\
Moisture content $(\%$ mass fraction) & In range $(60$ to 70$)$ \\
Particle size $(\mathrm{mm})$ & In range $(50$ to 150$)$ & Fourth \\
Fermentation temperature $\left({ }^{\circ} \mathrm{C}\right)$ & In range $(21$ to 34$)$ & Third \\
Response & & Maximize \\
Density 0 $\left(\mathrm{kg} / \mathrm{m}^{3}\right)$ & Maximize & Second \\
Density $1\left(\mathrm{~kg} / \mathrm{m}^{3}\right)$ & Minimize & First \\
Dimensional stability $(\%)$ & Maximize & \\
Tensile strength $(\mathrm{MPa})$ & \\
\hline
\end{tabular}

TABLE 7: Optimum conditions for producing oat straw pellets pretreated with TV52J and PC.

\begin{tabular}{lcccccccccc}
\hline $\begin{array}{l}\text { Fungal } \\
\text { strains }\end{array}$ & Number & $\begin{array}{c}\text { Fermentation } \\
\text { time }(d)\end{array}$ & $\begin{array}{c}\text { Moisture } \\
\text { content } \\
(\% \text { mass } \\
\text { fraction })\end{array}$ & $\begin{array}{c}\text { Particle } \\
\text { size } \\
(\mathrm{mm})\end{array}$ & $\begin{array}{c}\text { Fermentation } \\
\text { temperature } \\
\left({ }^{\circ} \mathrm{C}\right)\end{array}$ & $\begin{array}{c}\text { Density } \\
0 \\
\left(\mathrm{~kg} / \mathrm{m}^{3}\right)\end{array}$ & $\begin{array}{c}\text { Density } \\
\left(\mathrm{kg} / \mathrm{m}^{3}\right)\end{array}$ & $\begin{array}{c}\text { Dimensional } \\
\text { stability }(\%)\end{array}$ & $\begin{array}{c}\text { Tensile } \\
\text { strength } \\
(\mathrm{MPa})\end{array}$ & $\begin{array}{c}\text { Desirability } \\
\text { Untreated }\end{array}$ \\
TV52J & 1 & 33.96 & 70.00 & 150.00 & 22.00 & 1,104 & 1,070 & 1.07 & 0.395 & 0.844 \\
& 2 & 33.43 & 70.00 & 150.00 & 22.00 & 1,103 & 1,070 & 1.05 & 0.394 & 0.842 \\
PC & 1 & 35.00 & 70.00 & 50.00 & 22.00 & 1,108 & 1,068 & 1.14 & 0.294 & 0.817 \\
& 2 & 35.00 & 69.96 & 50.78 & 22.00 & 1,107 & 1,067 & 1.13 & 0.293 & 0.816 \\
\hline
\end{tabular}

organization of the latter was relatively loose and irregular. Figures 4(b) and 4(c) and 5(b) and 5(c) show that the exterior and interior structures of oat straw with pretreatment appeared large changes, such as loose surface, curved cracks, and expanded specific surface area. After biological pretreatment, parts of lignin, cellulose, and hemicellulose on the surface of oat straw were degraded, and the connections between single fibers became relatively loose which was beneficial to improve the quality of the compressive pellets. Similar results were proposed by Jiang et al. [39], Pan et al. [40], and Gao et al. [54].
Figure 6(a) shows that the cross-section microstructure of untreated oat straw had lots of fibrous tissue cells appeared in the cavity and interlinked which formed a honeycomb structure. Figures 6(b) and 6(c) show that the honeycomb structure of treated oat straw was destroyed because the lignin and hemicellulose used to connect the single fibers were largely removed or loosened. Shi et al. [49] investigated the solid-state cultivation on cotton stalks with PC and found the amount of lignin decreased $35.33 \%$. The degradation of lignin by different microorganisms has been widely studied, and the results showed 


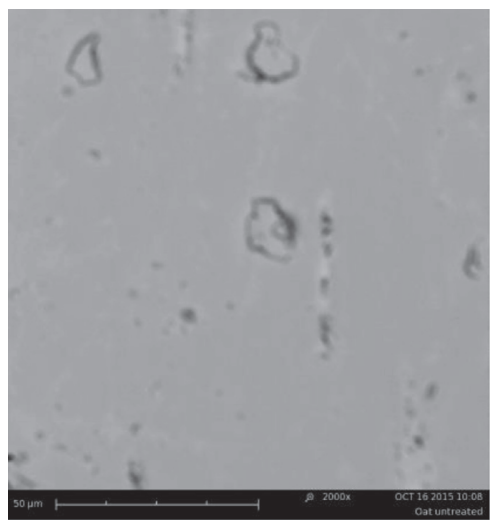

(a)

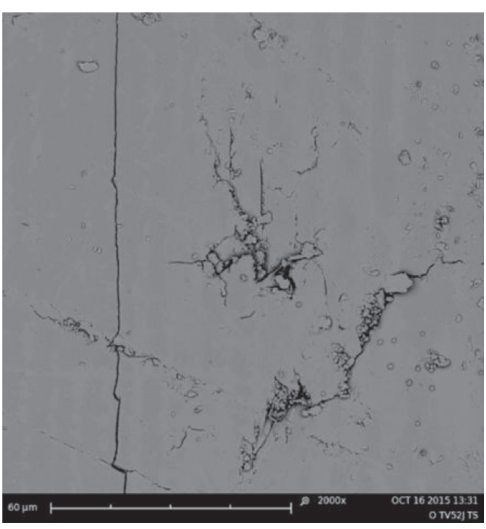

(b)

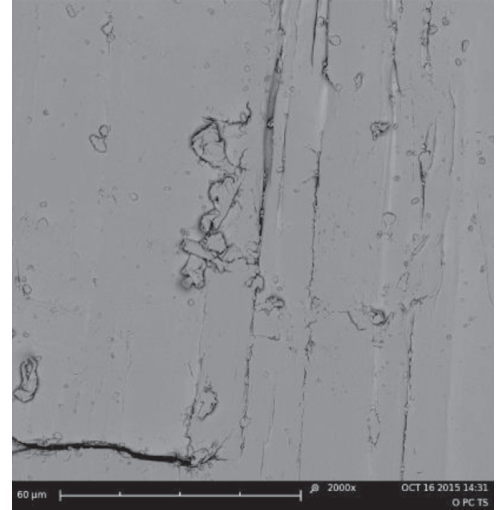

(c)

FIGURE 4: SEM images of the outer surface of the untreated and treated oat straw ( $\times 2,000$ times). (a) Untreated. (b) Treated with TV52J. (c) Treated with PC.

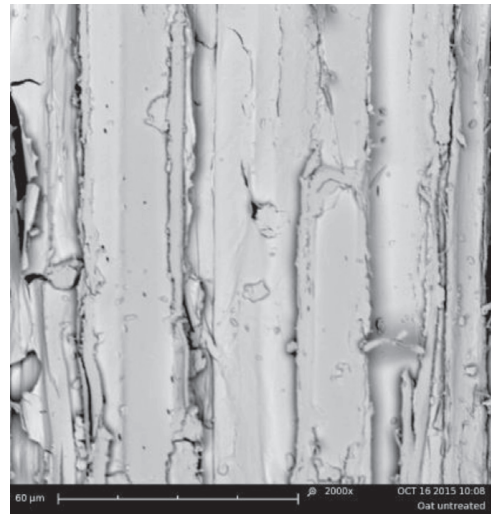

(a)

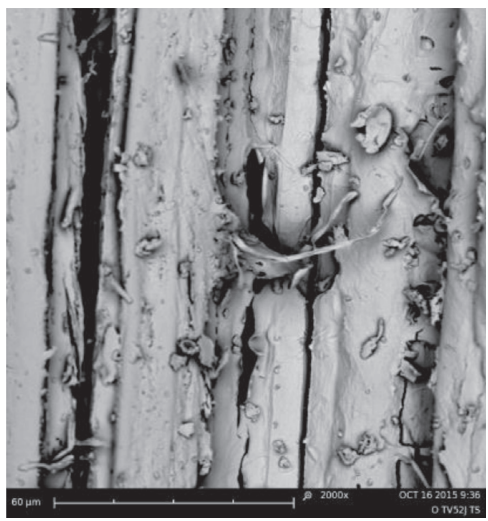

(b)

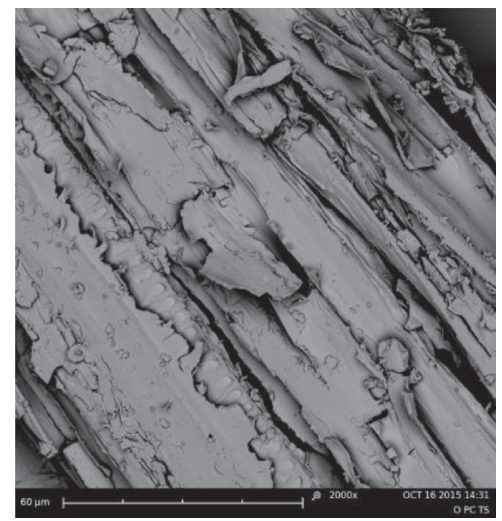

(c)

FIGURE 5: SEM images of the inner surface of the untreated and treated oat straw $(\times 2,000$ times). (a) Untreated. (b) Treated with TV52J. (c) Treated with PC.

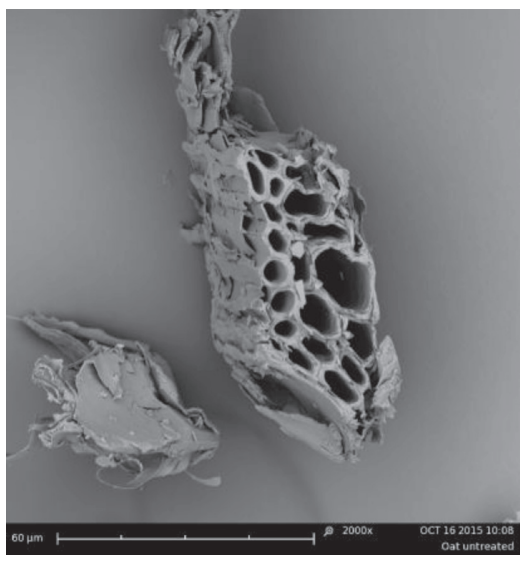

(a)

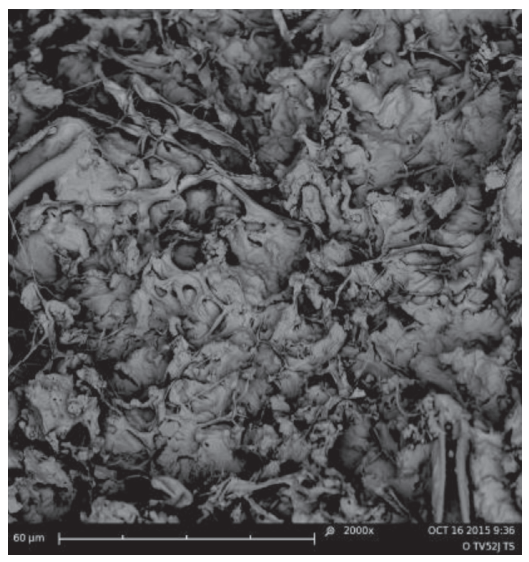

(b)

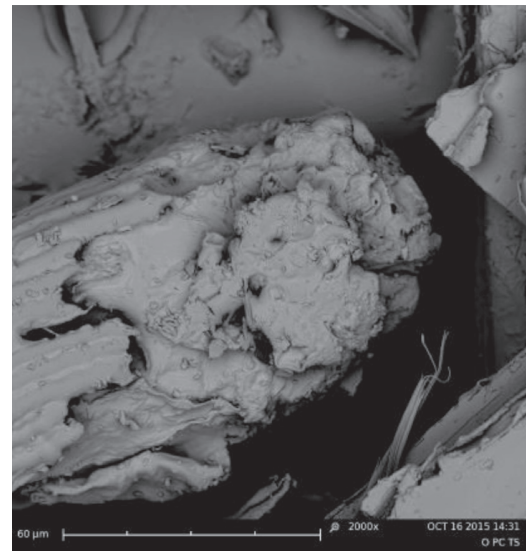

(c)

FIgURE 6: SEM images of cross section of the untreated and treated oat straw $(\times 2,000$ times). (a) Untreated. (b) Treated with TV52J. (c) Treated with PC. 
that inoculating lignin-degrading bacteria could accelerate the composting process and improve the composting quality [55].

\section{Conclusions}

The Box-Behnken design experiment taking fermentation time (days), moisture content (\%), particle size $(\mathrm{mm})$, and fermentation temperature $\left({ }^{\circ} \mathrm{C}\right)$ as independent parameters was used to predict tensile strength, dimensional stability, and pellet density of oat straw pellets pretreated by two fungal strains. The model was established, and variance analysis was carried out. Fermentation temperature significantly affected all the responses, and fermentation time significantly affected all the responses except density 1 of pellets produced by the oat straw pretreated with TV52J. Moisture content and particle size had significant effects on only 3 responses of pellets produced by oat straw pretreated with two fungal strains.

RSM was used to optimize all the pretreatment parameters for each fungal strain using selected response variables. The optimal combination for making oat straw pellets produced by the pretreated oat straw with two kinds of fungal strains showed that a long fermentation time (33.96 and 35 days), high moisture content (70\%), and low fermentation temperature $\left(22^{\circ} \mathrm{C}\right)$ were advantageous physical qualities of pellets. However, the influence of particle size depended on the fungal strain adopted. The optimized particle size of oat straw with pretreatment of TV52J was the biggest at $150 \mathrm{~mm}$, and the optimized fermentation time of oat straw with pretreatment of PC was the smallest at $50 \mathrm{~mm}$. Microscopic analysis showed that the connection between single fibers became relatively loose after pretreatment, which was advantageous to improve the quality of pellets. This research provided experience of solid-state fermentation on how to enhance the oat straw compressed pellet quality.

\section{Data Availability}

The data used to support the findings of this study are available from the corresponding author upon request.

\section{Conflicts of Interest}

The authors declare that they have no conflicts of interest.

\section{Acknowledgments}

The authors thank Jon Geissler for help with the fermentation experiments. They also expressed their gratitude for the National Natural Science Foundation of China (project approval no: 51508345), University Overseas Training Project of Liaoning Provincial Department of Education (project approval no: 2020GJWYB015), the Liaoning Province Natural Science Fund Project (project approval no: 2019-ZD-0717), the National Sparking Plan Project (2015GA650012), the Liaoning Province Natural Science Fund Project (project approval no: 2018055015), and the Basic Research Projects of Liaoning Province Higher Education Institutions (project approval no: 2017-32).

\section{References}

[1] F. J. Warren, P. Egginton, E. Barrow et al., "Background information: concepts, overviews and approaches. From impacts to adaptation: Canada in a changing climate," 2007, http://www.nrcan.gc.ca/environment/resources/publications/ impacts-adaptation/reports/assessments/2008/10253.

[2] K. L. Iroba, L. G. Tabil, S. Sokhansanj et al., "Producing durable pellets from barley straw subjected to radio frequency alkaline and steam explosion pretreatments," International Journal of Agricultural and Biological Engineering, vol. 7, no. 3, pp. 68-82, 2014.

[3] D. Rutz and R. Janssen, "Summary: the contribution of bioenergy to energy access and energy security," in SocioEconomic Impacts of Bioenergy Production, Springer, Berlin, Germany, 2014.

[4] A. Zhou and E. Thomson, "The development of biofuels in Asia," Applied Energy, vol. 86, pp. 11-20, 2009.

[5] M. Kashaninejad, L. G. Tabil, and R. Knox, "Effect of compressive load and particle size on compression characteristics of selected varieties of wheat straw grinds," Biomass and Bioenergy, vol. 60, pp. 1-7, 2014.

[6] D. Lu, L. G. Tabil, D. Wang, G. Wang, and S. Emami, "Experimental trials to make wheat straw pellets with wood residue and binders," Biomass and Bioenergy, vol. 69, pp. 287-296, 2014.

[7] L. Tabil, P. Adapa, and M. Kashaninej, "Biomass feedstock pre-processing-part 1: pre-treatment," Biofuel's Engineering Process Technology, IntechOpen, London, UK, pp. 411-439, 2011.

[8] S. Sokhansanj and A. F. Turhollow, "Biomass densificationcubing operations and costs for corn stover," Applied Engineering in Agriculture, vol. 20, no. 4, pp. 495-499, 2004.

[9] P. F. Zhang, Z. J. Pei, D. H. Wang et al., "Ultrasonic vibrationassisted pelleting of cellulosic biomass for biofuel manufacturing," Journal of Manufacturing Science and Engineering, vol. 133, no. 1, pp. 1-7, 2011.

[10] Y. Tang, W. Cong, J. Xu, P. Zhang, and D. Liu, "Ultrasonic vibration-assisted pelleting for cellulosic biofuels manufacturing: a study on in-pellet temperatures," Renewable Energy, vol. 76, no. 4, pp. 296-302, 2015.

[11] A. Demirbas and A. Sahin, "Evaluation of biomass residue 1. Briquetting waste paper and wheat straw mixtures," Fuel Process Technology, vol. 55, no. 2, pp. 175-183, 1998.

[12] X. Lu, M. R. Withers, N. Seifkar, R. P. Field, S. R. H. Barrett, and H. J. Herzog, "Biomass logistics analysis for large scale biofuel production: case study of loblolly pine and switchgrass," Bioresource Technology, vol. 183, pp. 1-9, 2015.

[13] K. Theerarattananoon, F. Xu, J. Wilson et al., "Effects of the pelleting conditions on chemical composition and sugar yield of corn stover, big bluestem, wheat straw, and sorghum stalk pellets," Bioprocess and Biosystems Engineering, vol. 35, no. 4, pp. 615-623, 2012.

[14] T. Canam, T. J. Dumonceaux, E. Record, and Y. Li, "White-rot fungi: the key to sustainable biofuel production?" Biofuels, vol. 4, no. 3, pp. 247-250, 2013.

[15] S. Li, P. Phitsuwan, R. Waeonukul et al., "Alkaline xylanolyticcellulolytic multienzyme complex from the novel anaerobic alkalithermophilic bacterium cellulosibacter alkalithermophilus and its hydrolysis of insoluble polysaccharides 
under neutral and alkaline conditions," Process Biochemistry, vol. 50, no. 4, pp. 643-650, 2015.

[16] R. L. Silveira, S. R. Stoyanov, S. Gusarov, M. S. Skaf, and A. Kovalenko, "Supramolecular interactions in secondary plant cell walls: effect of lignin chemical composition revealed with the molecular theory of solvation," The Journal of Physical Chemistry Letters, vol. 6, no. 1, pp. 206-211, 2015.

[17] F. Moreno, P. Zhang, G. Zhang, X. Tang, S. Wang, and S. Jin, "Enhancement of corn stover hydrolysis with rumen fluid pretreatment at different solid contents: effect, structural changes and enzymes participation," International Biodeterioration \& Biodegradation, vol. 119, pp. 405-412, 2017.

[18] T. A. Phan, J. Lin, and J. Z. Cao, "Properties of plywood with lignin based adhesive and the curing behavior of adhesive," Thermosetting Resin, vol. 33, no. 1, pp. 45-49, 2018.

[19] M. Shaw, "Feedstock and process variables influencing biomass densification," M.S. thesis, University of Saskatchewan, Department of Agricultural and Bioresource Engineering, Saskatoon, Canada, 2008.

[20] C. Wan and Y. Li, "Fungal pretreatment of lignocellulosic biomass," Biotechnology Advances, vol. 30, no. 6, pp. 14471457, 2012.

[21] S. H. Mood, A. H. Golfeshan, M. Tabatabaei et al., "Lignocellulosic biomass to bioethanol, a comprehensive review with a focus on pretreatment," Renewable and Sustainable Energy Reviews, vol. 27, pp. 77-93, 2013.

[22] N. Sarkar, S. K. Ghosh, S. Bannerjee, and K. Aikat, "Bioethanol production from agricultural wastes: an overview," Renewable Energy, vol. 37, no. 1, pp. 19-27, 2012.

[23] D. SalvachúaAikat, A. Prieto, M. López-Abelairas, T. LuChau, Á. T. Martínez, and M. J. Martínez, "Fungal pretreatment: an alternative in second-generation ethanol from wheat straw," Bioresource Technology, vol. 102, no. 16, pp. 7500-7506, 2011.

[24] B. C. Saha, N. Qureshi, G. J. Kennedy, and M. A. Cotta, "Biological pretreatment of corn stover with white-rot fungus for improved enzymatic hydrolysis," International Biodeterioration \& Biodegradation, vol. 109, pp. 29-35, 2016.

[25] C. E. Cotta, B. E. Dale, R. T. Elander, M. Holtzapple, M. R. Ladisch, and Y. Y. Lee, "Coordinated development of leading biomass pretreatment technologies," Bioresource Technology, vol. 96, no. 18, pp. 1959-1966, 2005.

[26] T. Canam, J. R. Town, A. Tsang, T. A. McAllister, and T. J. Dumonceaux, "Biological pretreatment with a cellobiose dehydrogenase-deficient strain of Trametes versicolor enhances the biofuel potential of canola straw," Bioresource Technology, vol. 102, no. 21, pp. 10020-10027, 2011.

[27] Z. Anwar, M. Gulfraz, and M. Irshad, "Agro-industrial lignocellulosic biomass a key to unlock the future bio-energy: a brief review," Journal of Radiation Research and Applied Sciences, vol. 7, no. 2, pp. 163-173, 2014.

[28] I. Isroi, R. Millati, S. Syamsiah et al., "Biological pretreatment of lignocelluloses with white-rot fungi and its applications: a review," BioResources, vol. 6, no. 4, pp. 5224-5259, 2011.

[29] F. E. Fernández, D. F. J. Ruiz, and A. T. Martínez, "Engineering a fungal peroxidase that degrades lignin at very acidic pH," Biotechnology for Biofuels, vol. 7, no. 1, p. 114, 2014.

[30] U. Hölker and J. Lenz, "Solid-state fermentation-are there any biotechnological advantages?" Current Opinion in Microbiology, vol. 8, no. 3, pp. 301-306, 2005.

[31] C. Krishna, "Solid-state fermentation systems-an overview," Critical Reviews in Biotechnology, vol. 25, no. 1-2, pp. 1-30, 2005.
[32] A. Jain, C. K. Morlok, and J. M. Henson, "Comparison of solid-state and submerged-state fermentation for the bioprocessing of switchgrass to ethanol and acetate by Clostridium phytofermentans," Applied Microbiology and Biotechnology, vol. 97, no. 2, pp. 905-917, 2013.

[33] F. Wirawan, C.-L. Cheng, W.-C. Kao, D.-J. Lee, and J.-S. Chang, "Cellulosic ethanol production performance with SSF and SHF processes using immobilized Zymomonas mobilis," Applied Energy, vol. 100, pp. 19-26, 2012.

[34] P. Alvira, E. Tomás-Pejó, M. Ballesteros, and M. J. Negro, "Pretreatment technologies for an efficient bioethanol production process based on enzymatic hydrolysis: a review," Bioresource Technology, vol. 101, no. 13, pp. 4851-4861, 2010.

[35] American Society of Agricultural and Biological Engineers, "ASAE standardsNegro 358.2-moisture measurement-forages," in ASABE Standards, vol. 608, American Society of Agricultural and Biological Engineers, St. Joseph, MI, USA, 2006.

[36] T. Dumonceaux, K. Bartholomew, L. Valeanu, T. Charles, and F. Archibald, "Cellobiose dehydrogenase is essential for wood invasion and nonessential for kraft pulp delignification by Trametes versicolor," Enzyme and Microbial Technology, vol. 29, no. 8-9, pp. 478-489, 2001.

[37] D. X. Ming, Higher Biostatistics, China Agricultural Science and Technology Press, Beijing, China, 2006.

[38] Y. J. Fan, Z. C. Zhang, and K. Y. Hu, "Optimization of lingnin degradation in straw by penicillium based on multiple quadratic regression analysis and orthogonal test," Journal of Biomathematics, vol. 32, no. 4, pp. 505-513, 2017.

[39] H. Jiang, Y. Zhang, and X. Wang, "Effect of lipases on the surface properties of wheat straw," Industrial Crops and Products, vol. 30, no. 2, pp. 304-310, 2009.

[40] G. W. Pan, X. L. Hou, S. Zhu et al., "Preparation and properties of wheat straw fibersfor composites," Transactions of the Chinese Society of Agricultural Engineering, vol. 28, no. 9, pp. 287-291, 2012.

[41] M. Asgher, M. J. Asad, and R. L. Legge, "Enhanced lignin peroxidase synthesis by Phanerochaete chrysosporium in solid state bioprocessing of a lignocellulosic substrate," World Journal of Microbiology and Biotechnology, vol. 22, no. 5, pp. 449-453, 2006.

[42] J. Shi, M. Chinn, and R. Sharmashivappa, "Microbial pretreatment of cotton stalks by solid state cultivation of Phanerochaete chrysosporium," Bioresource Technology, vol. 99, no. 14, pp. 6556-6564, 2008.

[43] F. Zadrazil and H. Brunnert, "Investigation of physical parameters important for the solid-state fermentation of straw by white rot fungi," European Journal of Appled Microbiology Biotechnology, vol. 11, pp. 183-188, 1981.

[44] I. D. Reid, "Biological delignification of aspen wood by solidstate fermentation with the white-rot fungus merulius tremellosus," Applied and Environmental Microbiology, vol. 50, no. 1, pp. 133-139, 1985.

[45] I. D. Reid, "Solid-state fermentations for biological delignification," Enzyme and Microbial Technology, vol. 11, no. 12, pp. 786-803, 1989.

[46] C. Wan and Y. Li, "Microbial delignification of corn stover by Ceriporiopsis subvermispora for improving cellulose digestibility," Enzyme and Microbial Technology, vol. 47, no. 1-2, pp. 31-36, 2010.

[47] D. M. Rudakiya and A. Gupte, "Degradation of hardwoods by treatment of white rot fungi and its pyrolysis kinetics studies," International Biodeterioration \& Biodegradation, vol. 120, pp. 21-35, 2017. 
[48] F. A. Keller, J. E. Hamilton, and Q. A. Nguyen, "Microbial pretreatment of biomass," Biotechnology for Fuels and Chemicals, Springer, Berlin, Germany, 2003.

[49] J. Shi, R. R. Sharma-Shivappa, M. Chinn, and N. Howell, "Effect of microbial pretreatment on enzymatic hydrolysis and fermentation of cotton stalks for ethanol production," Biomass and Bioenergy, vol. 33, no. 1, pp. 88-96, 2009.

[50] C. Howell and Y. Li, "Microbial pretreatment of corn stover with Ceriporiopsis subvermispora for enzymatic hydrolysis and ethanol production," Bioresource Technology, vol. 101, no. 16, pp. 6398-6403, 2010.

[51] W. Gao, L. G. Tabil, Q. Liu, R. Zhao, and M. Zhang, "Experimental study on the effect of solid-state fermentation on pellet density and strength of corn stover," Journal of Biobased Materials and Bioenergy, vol. 13, no. 6, pp. 840-847, 2019.

[52] S. Mani, L. G. Tabil, and S. Sokhansanj, "Grinding performance and physical properties of wheat and barley straws, corn stover and switchgrass," Biomass and Bioenergy, vol. 27, no. 4, pp. 339-352, 2004.

[53] K. Mahdi, L. G. Tabil, and K. Ron, "Effect of compressive load and particle size on compression characteristics of selectedvarieties of wheat straw grinds," Biomass and Bioenergy, vol. 60, pp. 1-7, 2014.

[54] W. Gao, L. G. Tabil, T. Dumonceaux, S. Espinel Ríos, and R. Zhao, "Optimization of biological pretreatment to enhance the quality of wheat straw pellets," Biomass and Bioenergy, vol. 97, pp. 77-89, 2017.

[55] M. J. Lopez, M. del Carmen Vargas-García, F. Suárez-Estrella, and J. Moreno, "Bio-delignification and humification of horticultural plant residues by fungi," International Biodeterioration \& Biodegradation, vol. 57, no. 1, pp. 24-30, 2006. 